Itzel Cristina Ibarra Serna 


\section{La dirección del tiempo y la causalidad}

\section{Introducción}

Lo que me propongo exponer es una comparación de sistemas, el de la dirección del tiempo con el sistema de la causalidad, donde me parece más básico o plausible en una teoría metafísica elegir la dirección del tiempo con un sentido de antes a después, porque de esta manera nos permite dar una explicación coherente y lógica de la realidad que estamos percibiendo.

El humano es el único ser capaz sobre la tierra de apropiarse de términos y darles un sentido lingüístico para comunicar necesidades y deseos. Podemos hacer una bifurcación entre el lenguaje físico y el lenguaje de la mente. Dar una descripción de lo que percibe la mente humana es un problema filosófico; hablar, por ejemplo, de la naturaleza del tiempo es una cuestión de reflexión, porque cuando tratamos de explicar la naturaleza del mundo o cuando queremos conocer el porqué de la existencia de la vida, nos vemos enfrentados a colocarlo dentro de un suceso, donde un acontecimiento indica el significado del tiempo en cada suceso. La dirección del tiempo marca el inicio de un proceso, pero ¿a qué tipo de proceso nos estamos refiriendo?, ¿ podría ser acaso uno evolutivo o uno que involucre la entropía?

La dirección del tiempo involucra la noción de la causalidad: al decir que un acto ocurrió debido a otro que sucedió antes. El sistema de la causalidad nos ayuda mucho a hacer a un lado todas las cuestiones donde aún no podemos comprender el porqué de los hechos. Por ejemplo, la finalidad de la vida humana.

Considero que la revisión de este tema es importante en el quehacer filosófico, porque al dar una justificación del sentido direccional del tiempo se está intentando ofrecer la respuesta de por qué los hechos ocurren de tal manera y no de otra. Así, también 
ampliamos nuestras concepciones para entender la complejidad de la realidad.

\section{Kant}

Uno de los filósofos más destacados por sus grandes aportaciones a diversas disciplinas fue Immanuel Kant, quien retoma la idea de la causalidad como una relación objetiva:

Yo percibo que los fenómenos se suceden unos a otros [...]. Conecto, pues, propiamente, dos percepciones en el tiempo. Pero la conexión no es obra del mero sentido ni de la intuición [...] Sólo soy consciente de que mi imaginación coloca un [estado] antes, y el otro después; [...] por la mera percepción queda indeterminada la relación objetiva de los fenómenos que se siguen unos a otros. Para que ésta sea conocida como determinada, la relación entre los dos estados debe ser pensada de tal manera, que con ella se determine como necesario cuál de ellos debe ser colocado antes, y cuál después, y no a la inversa. ${ }^{1}$

Podríamos decir, entonces, que la causalidad depende de la manera en la que son percibidos los fenómenos, y que al describir cómo de hecho sucedieron los acontecimientos ya se está implicando la dirección del tiempo.

Al llevar a cabo un acto, lo hacemos para que ocurra otro, y por lo general actuamos para obtener la cosa secundaria; si partimos de una acción voluntaria humana, las leyes causales pasan a un segundo plano. Si se llega al acto sólo por voluntad o por algún tipo de deseo, no tiene sentido provocar o esperar una respuesta, una causa. Pero no sucede lo mismo con el tiempo, al menos de la manera como lo comprendemos, éste siempre tiene el mismo enfoque hacia el futuro.

1 Kant, Immanuel, Crítica de la razón pura (trad. Mario Caimi), Ed. FCE/ UNAM, México, 2009 [1781], pp. 232-233. 


\section{Dummett}

Michael Dummett afirma lo siguiente: "La dirección temporal de la causalidad, de antes a después, proviene de considerar la causa como el inicio de un proceso: es decir el hecho de que en algún momento se esté desarrollando un proceso queda suficientemente explicado si podemos explicar qué lo inició." ${ }^{2}$ Con esta idea me atrevo a decir que es, entonces, posible que haya algún tipo de hecho donde está estrechamente relacionada la dirección del tiempo con la causalidad. Si bien es un tipo de proceso, se debe, entonces, establecer al menos en una serie de causas que lo generen provocando al mismo tiempo los mismos números de efectos.

En el artículo "Causando al pasado", Dummett da un ejemplo de cómo sería nuestra concepción del tiempo si ocurrieran los hechos de manera contraria, y si fuéramos meramente observadores y no agentes de la realidad:

Los árboles se desarrollan haciéndose gradualmente más pequeños, hasta que se reducen a una semilla de manzana; luego, poco a poco se forma una manzana alrededor de la semilla a partir de ingredientes que se encuentran en la tierra; en cierto momento la manzana rueda por la tierra y ganando gradualmente impulso, bota unas cuantas veces, y de repente se eleva y haciendo un ruido se une a la rama de un manzano. ${ }^{3}$

Entendamos al agente como el ser capaz de alterar el orden de los efectos, y al observador como aquel ser que sólo da por entendido los sucesos y no es capaz de alterar algún orden en los efectos. Dummett asume perspectivas distintas por parte de ambos sujetos, ya sea como agente o como observador; en la primera, el mundo es de tal manera que se apropia de la noción de causalidad asociada con la dirección temporal de antes a después y no a la inversa, y la segunda donde sí se concibe la noción de causalidad como dirección apropiada, y en cuanto para los observadores tal concepción de la causa es invertida. Hay varios asuntos en los que el ser humano actúa como observador, por ejemplo, sólo podemos

2 Dummett, Michel, La verdad y otros enigmas (trad. por Alfredo Herrera Patiño), Ed. FCE, México, 1990, p. 409.

3 Ibidem p. 423. 
observar a los cielos y otros planetas. Pero a pesar de ello el ser humano se las ha ingeniado para hacer posible la intervención en factores de tipo de natural, provocando graves daños al enajenarlos y sobreexplotarlos para un bien económico y no sustentable.

Además, cuando analizamos acciones humanas hay muchas que parecen no tener sentido, por ejemplo los ruegos o las súplicas a la divinidad. En este tipo de enunciados el contenido parece irrelevante, porque si de antemano se sabe que ocurrió un accidente y que sólo queda esperar a saber quiénes sobrevivieron, esto habría sucedido debido a que de hecho así tenían que ocurrir los acontecimientos, por lo que el ruego o la súplica no necesariamente habrían tenido un efecto en el accidente.

Sin embargo, parece que hay cosas que ocurren sin explicaciones lógicas, como la danza que realiza el jefe de una tribu para que un grupo de jóvenes actúe de manera valiente enfrentado a una manada de leones. El jefe es capaz de soportar seis días danzando, a sabiendas de que el viaje al sito donde los jóvenes encontrarían los leones estaba a dos días y que posteriormente duraban dos días de batalla - de cobardía o de valentía, por la cual bailaba el jefe de la tribu-, y finalmente les daban dos días para regresar a la tribu. No obstante, sería más fácil comprender que el jefe de la tribu bailara solamente los primeros cuatro días, ya que había un grupo de observadores que regresaban con el mensaje mucho antes de que llegara el grupo de jóvenes. Entonces, Dummett plantea la posibilidad de aterrizar acciones triviales, como las súplicas o ruegos, como una forma de comprender la causalidad como mera relación objetiva con la realidad fenoménica.

Sostengo que hay una variación de nociones que quedan al aire; vemos cómo el reloj siempre avanza, siempre es un microsegundo después y no uno antes; en verdad ¿podríamos imaginar un mundo o quizá un universo completo, donde el tiempo tenga un sentido contrario? Y así, pues, nuestros actos voluntarios secundarios podrían afectar a las cosas que sucedieron antes, como esa manzana que en vez de caer al suelo, sube del suelo y se coloca en la rama del árbol de manzano con un especial ruido. Si asumimos esta postura, estaremos asimilando un espacio donde el tiempo tenga una dirección distinta a la que creemos que es nuestra verdadera realidad. 


\section{Álvarez}

Por otra parte, Toledo Álvarez muestra que la teoría causal del tiempo (TCT) carece de principio y fin. Porque en ella se da la explicación y en ella misma se argumenta la conclusión. Se pretende justificar la dirección del tiempo mediante la orientación causaefecto teniendo una explicación asimétrica, o quizá mejor dicho que la orientación temporal antes-después tiene una base causal, es decir, se explica por las diversas relaciones causales que se dan en la naturaleza. ${ }^{4}$ Por ello, según dicho autor, no es relevante darnos cuenta de cuál sistema precede a cuál, si el del tiempo a la causalidad o viceversa; pero el tiempo tiene el mismo sentido de antes a después y no a la inversa. Entonces, ¿qué sucede con las realidades que no podemos predecir? Aquellas realidades donde sólo se puede ser meramente un observador y no un agente. Entraría la posibilidad de que existiera algún otro universo paralelo, donde el tiempo fuera asimétrico a la dirección de la causalidad. Si la especie humana acepta y asimila al tiempo con un solo sentido direccional es porque se ha propuesto planificar una vida, siendo capaz de crear su propio destino.

Al criticar la TCT desde la perspectiva de Mellor, quien afirma que la probabilidad de un suceso es en realidad una propiedad de hechos anteriores, propone que los hechos presentados como suceso de antes a después son una mera coincidencia en la manera de ver la causalidad de causa a efecto y concluye que los hechos son simultáneos.

A través de suposiciones, según las cuales los hechos mantienen una relación independiente de la probabilidad temporal, ocurren en un momento preciso y en un lugar específico, estos sucesos tendrán que ser dados en un mundo dinámico, lo que hace parecer que la dirección del tiempo es asimétrica a la causalidad. Entonces, lo que quedaría pendiente de esta concepción al aceptar meras coincidencias al transcurrir los hechos es esta pregunta: ¿cómo podríamos justificar los hechos que tienen una casualidad junto con el tiempo? Solamente hay una respuesta: si hay posibilidad de entender un universo paralelo donde el tiempo transcurra en un sentido contrario, por qué no entender uno donde la dirección de la causalidad sea como una coincidencia a los hechos con el tiempo.

4 Álvarez, Toledo, en Causalidad y tiempo: el sentido de una reducción, por Teorema, Vol. XXVII, 2008, p. 29. 


\section{Conclusión}

Las explicaciones que estos autores proyectan produjeron a mi entendimiento una modificación a la manera de percibir la dirección del tiempo. Es durante el tiempo donde se presentan los cambios, y si los cambios son una modificación, sea total o parcial de un objeto, es porque pertenecen a la dimensión espacio-temporal, al igual que este proceso, el tiempo siempre llevará, al menos en este universo, un proceso de antes a después. Hay que aceptar que no tiene sentido realizar actos con fines pasados (como súplicas y ruegos), pues ya que los hechos se hicieron realidad, aquéllos están lejos de poder alterarlos. Al igual que la dirección de causalidad, donde siempre concebimos primero el efecto y posteriormente la causa, si vemos fijamente una línea, podemos observar un punto que se sigue de otro punto y el espacio puede ocuparse así; hay un segundo que sigue a otro segundo, para darle forma y sentido al tiempo. Puedo sostener que la dirección lineal del tiempo de pasado a futuro es simétrica a la causalidad. Sin embargo, considero que es más sostenible la idea de que el sistema de la dirección del tiempo de antes a después contiene más parsimonia ontológica que el sistema de la causalidad. Hay un efecto, se realiza un acto, hay una intención de por medio. Resulta una causa, que tiene el mismo sentido de las manecillas del reloj, pues el tiempo avanza mientras la causa del efecto va apareciendo.

Queda expuesta mi postura ante dos maneras de asimilar la dirección temporal y la dirección de la causalidad. Es importante sostenerse de al menos una postura, para darle sentido a los hechos cotidianos, para planear una vida, o para vivir sin darse cuenta de que cuando el tiempo avanza, hay muchos efectos que se hicieron causa y ésta fue el efecto de otra. 
